\title{
Percepção de Plágio Acadêmico entre Estudantes e Professores de Cursos de Graduação e Pós-Graduação na Modalidade a Distância
}

Daniel Seitenfus, UFSM/Santa Maria, daniel.seitenfus@hotmail.com Bruna V. dos Santos, UFSM/Frederico Westphalen, contatobrunavitoria@gmail.com

Edimar Manica, IFRS/Ibirubá, edimar.manica@ibiruba.ifrs.edu.br Solange Pertile, UFSM/Frederico Westphalen, solange.pertile@ufsm.br

Resumo: O presente artigo apresenta um estudo quali-quantitativo dirigido com o objetivo de identificar os motivos que podem levar os alunos de cursos ofertados na modalidade a distância a plagiarem e como os professores têm atuado a respeito deste problema nas atividades acadêmicas. Os resultados obtidos mostram que os professores consideram importante relatar os casos de plágio aos alunos para entendimento e correção, não se atendo apenas na punição. Já os estudantes demonstram a falta de conhecimento acerca das normas de citação, o que pode causar o plágio não intencional. Diante disso, julga-se necessário aplicar ações junto a comunidade acadêmica para conscientização da importância da utilização de fontes confiáveis e da atribuição correta aos autores originais, evitando assim a violação de direitos autorais.

Palavras-chave: Direitos autorais; Ensino a distância; Plágio.

\section{Perception of Academic Plagiarism between Students and Professors of Graduation and Post-Graduate Courses in the Distance Modalities}

\begin{abstract}
This work presents a qualitative-quantitative study with the objective of identifying the reasons that can lead undergraduate students in distance modality to plagiarize and how the professors have acted on this problem in academic activities. The results show that the professors consider it important to report plagiarism cases to the students for understanding and correction, not only being punished. The students demonstrate the lack of knowledge about citation standards, which can cause unintended plagiarism. Given this, it is considered necessary to apply to the academic community actions to raise awareness of the importance of using reliable sources and correct attribution to the original authors, thus avoiding copyright infringement.
\end{abstract}

Keywords: Copyright; Distance learning; Plagiarism.

\section{Introdução}

Diante do aumento das informações disponibilizadas na internet, o plágio tem se tornado um problema universal. A prática de plágio tem ocorrido tanto em cursos presenciais como em cursos na modalidade de educação a distância (EaD). No entanto, devido ao crescimento do número de alunos matriculados na EaD (INEP, 2016, p. 7), não se torna uma tarefa trivial para os professores verificar a originalidade em meio a uma grande quantidade de trabalhos (Silva, 2008).

De acordo com estudos encontrados na literatura (Mccabe, 2005; Youmans, 2011), percebe-se que o problema de plágio vem ocorrendo tanto no âmbito acadêmico como científico. Além disso, casos em que o estudante comete plágio acidentalmente ou de forma não intencional pode levá-lo a receber as mesmas punições que um caso intencional. De acordo com o Código de Boas Práticas Científicas da Fapesp (2014, p. 31), "o plágio é a utilização de ideias ou formulações verbais, orais ou escritas de outrem sem dar-lhe por elas, expressa e claramente, o devido crédito, de modo a gerar razoavelmente a percepção de que sejam ideias ou formulações de autoria própria”. 
Uma série de estudos tem relatado a alta prevalência de plágio no meio acadêmico. Mccabe (2005) realizou uma pesquisa com mais de 80.000 alunos nos EUA e Canadá e descobriu que $36 \%$ dos estudantes de graduação e $24 \%$ dos estudantes de pós-graduação admitem ter copiado ou parafraseado frases da Internet sem fazer a devida referência a obra original.

Um estudo realizado na Universidade de São Paulo apontou que $42 \%$ das unidades não apresentam nenhuma informação sobre a definição de plágio. Este estudo também identificou que não há orientações para a sua prevenção ou medidas punitivas caso houver algum caso (Ferreira, 2014). Estudos também apontam que estudantes de graduação e pós-graduação têm grandes dificuldades de escrever textos acadêmicos científicos, tanto na organização formal do texto como em compreender as fontes lidas e referenciá-las corretamente (Figueiredo e Bonini, 2006; Bessa, 2007).

Sendo assim, se torna cada vez mais necessário dedicar esforços para combater o plágio através da conscientização no ambiente acadêmico e uso de ferramentas de detecção (Alzahrani, 2011; Pertile et al., 2011; Pertile et al., 2015). Em 2011, a Coordenação de Aperfeiçoamento de Pessoal de Nível Superior (Capes) emitiu um documento para as instituições de ensino recomendando que adotem políticas de conscientização e informação sobre a propriedade intelectual, visando coibir a prática do plágio quando da redação de teses, monografias, artigos e outros textos por parte de alunos e outros membros de suas comunidades (Capes, 2011, p. 1).

Com base nesses levantamentos, este artigo apresenta uma pesquisa realizada com alunos e professores de cursos de graduação e pós-graduação ofertados na modalidade a distância, visando identificar se os alunos têm cometido plágio e quais as principais causas. O estudo também buscou identificar se os professores estão amparados de informações para auxiliar os alunos na prevenção e ação quando identificar um caso de plágio.

Este artigo está organizado como segue. Esta seção descreve os objetivos e a justificativa que norteou o desenvolvimento do estudo. A Seção 2 apresenta os conceitos e tipos de plágio comumente apresentados no estado da arte. A Seção 3 detalha a metodologia adotada. A Seção 4 descreve os resultados obtidos. Por fim, a Seção 5 apresenta as considerações finais e discute os trabalhos futuros.

\section{Definição e Tipos de Plágio}

Plágio é uma das formas mais graves de má conduta acadêmica. Ele é definido como o ato de apropriar-se de ideias, palavras ou obras de outra pessoa sem dar crédito à fonte original (Anderson; Steneck, 2011; Stein; Eissen, 2006). No Brasil, violar os direitos autorais é crime e está descrito no Art. 184 - Código Penal, que prevê pena de detenção de 3 (três) meses a 1 (um) ano, ou multa.

De acordo com a iThenticate (2013), pode-se definir diferentes tipos de plágio:

(i) Atribuição enganosa - omitir autores que colaboraram com o manuscrito; (ii) Completo - copiar um manuscrito completo e enviar com o próprio nome; (iii) Duplicação - reutilizar trabalhos anteriores de sua própria autoria sem referenciar, também classificado como autoplágio (Stein; Eissen, 2006); (iv) Fonte inválida referenciar uma fonte incorreta ou inexistente; (v) Fonte secundária - usar uma fonte secundária, mas citar apenas a fonte primária; (vi) Paráfrase - reescrever ideias de um autor com as próprias palavras sem dar crédito a fonte original; (vii) Pesquisa repetida - repetir a metodologia de um estudo com dados diferentes sem atribuir a fonte; (viii) Replicação - repetir o mesmo trabalho e enviar para diferentes lugares para publicação; (iv) Verbatim - copiar palavra por palavra do trabalho de outro autor sem destacar (recuo, aspas, etc.) e/ou referenciar a fonte original. 
Os autores Carmo e Kennedy (2009) também consideram o plágio traduzido um método de assumir a autoria de trabalhos de terceiros a partir da tradução de uma obra para outro idioma sem a devida atribuição ao autor original. O IEEE ${ }^{1}$ disponibiliza orientações acerca de diferentes níveis de plágio, considerando os tipos identificados acima. Além disso, considera como referência vaga ou incorreta casos em que não ocorre o uso de aspas em uma citação direta.

\section{Metodologia}

Os procedimentos metodológicos basearam-se em uma pesquisa qualiquantitativa. Conforme a Tabela 1, foram aplicados dois questionários, o primeiro foi adaptado de Guedes e Filho (2014), visando permitir compreender as dificuldades dos alunos em relação ao plágio. $\mathrm{O}$ segundo instrumento foi elaborado com o objetivo de identificar a conduta dos professores na prevenção, detecção e punição do plágio no ambiente acadêmico. Além disso, algumas questões buscaram nortear o conhecimento dos professores acerca da existência de politicas institucionais quanto ao plágio.

Tabela 1: Instrumento de coleta de dados

\begin{tabular}{|l|}
\hline \multicolumn{1}{|c|}{ Questionário para Alunos } \\
\hline Os alunos têm conhecimento que plágio é crime? \\
\hline Quais tipos de plágio são considerados pelos alunos? \\
\hline Os estudantes conhecem as normas de formatação de citações? \\
\hline Quais situações você considera como sendo plágio? \\
\hline Quais os tipos de fontes de pesquisa utilizadas pelos estudantes? \\
\hline Qual a ação dos estudantes ao encontrarem artigos retratados? \\
\hline Os alunos recebem orientações sobre plágio? \\
\hline \multicolumn{1}{|c|}{ Questionário para Professores } \\
\hline Como os professores identificam o plágio? \\
\hline Quais as ações adotadas pelos professores ao identificar a ocorrência de plágio? \\
\hline Você conhece as medidas definidas pelas políticas internas da sua universidade que devem ser aplicadas \\
a partir da identificação da ocorrência de plágio? \\
\hline Qual a frequência de identificação de plágio na EaD? \\
\hline
\end{tabular}

Os instrumentos foram construídos por meio da ferramenta Google Forms ${ }^{2}$ e enviados por e-mail para a coordenação de 25 cursos ofertados na modalidade a distância, desses, 13 são cursos de graduação e 12 de pós-graduação. O questionário foi anônimo e não identificou a que curso o respondente estava vinculado.

Para a análise e a apresentação dos resultados, foi estabelecida uma articulação entre o referencial teórico e as respostas obtidas pelos questionários. Possibilitando assim perceber as dificuldades encontradas pelos alunos, e as ações dos professores em relação ao plágio no meio acadêmico.

\section{Resultados}

Obteve-se um total de 116 respondentes. Desses, 88 são alunos, entre eles, 54 de graduação $(61,4 \%)$ e 34 de pós-graduação $(38,6 \%)$. Dos professores foram 28 respondentes, 13 atuam em cursos de graduação, 7 em cursos de pós-graduação e $8 \mathrm{em}$ ambos. A seguir são discutidos os resultados obtidos para cada questão de pesquisa.

1 Disponível em: http://www.ieee.org/publications_standards/publications/rights/plagiarism_FAQ.html. 2 Disponivel em: https://www.google.com/forms/about/. 


\section{Q1: Os alunos têm conhecimento que plágio é crime?}

A Figura 1 apresenta o conhecimento dos alunos sobre como a legislação brasileira vigente considera o plágio. A maioria dos alunos demonstrou conhecer que a prática de plágio configura-se crime, resultando em $96,6 \%$, e apenas $3,4 \%$ não souberam informar ou acreditam que plágio não é considerado crime, sendo esses apenas alunos de graduação.

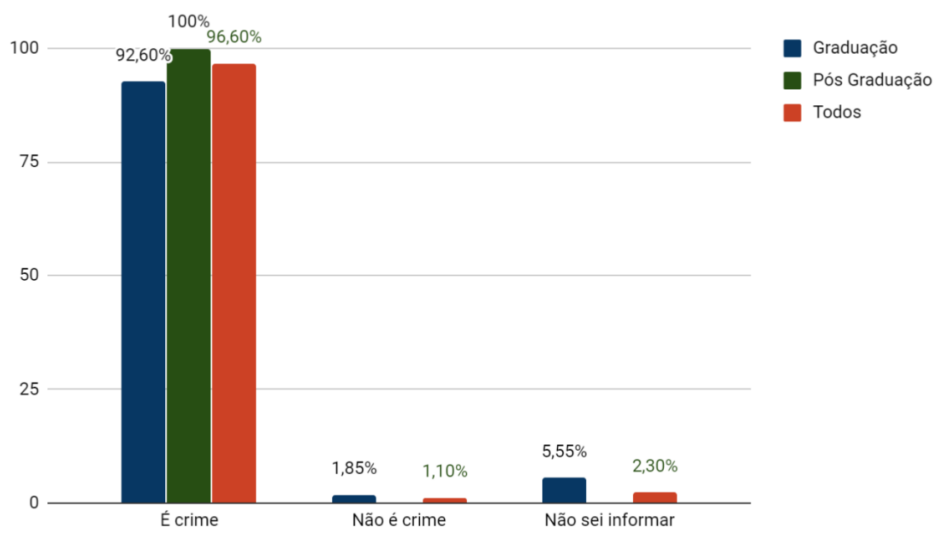

Figura 1: Conhecimento sobre plágio na legislação brasileira.

\section{Q2: Quais tipos de plágio são considerados pelos alunos?}

Quando questionados sobre quais situações são consideradas plágio, foi possível identificar que $98,9 \%$ dos respondentes compreendem que a cópia fiel de um texto ou fragmento sem referenciá-lo configura-se plágio. O uso de um texto com fragmentos de outros autores sem a devida referência foi considerado por $50 \%$ dos respondentes. Já a paráfrase, que se caracteriza pelo uso de um trecho reescrito com as próprias palavras a partir da ideia de um autor sem atribuição de crédito, apesar de ser considerada a forma mais comum de plágio e também o mais grave entre pesquisadores (iThenticate, 2013), foi considerado por apenas $36,4 \%$ dos respondentes. Ressalta-se também que não há um conhecimento maior sobre os tipos de plágio dos alunos de pós-graduação comparados com os de graduação. A Figura 2 apresenta os resultados desta questão.

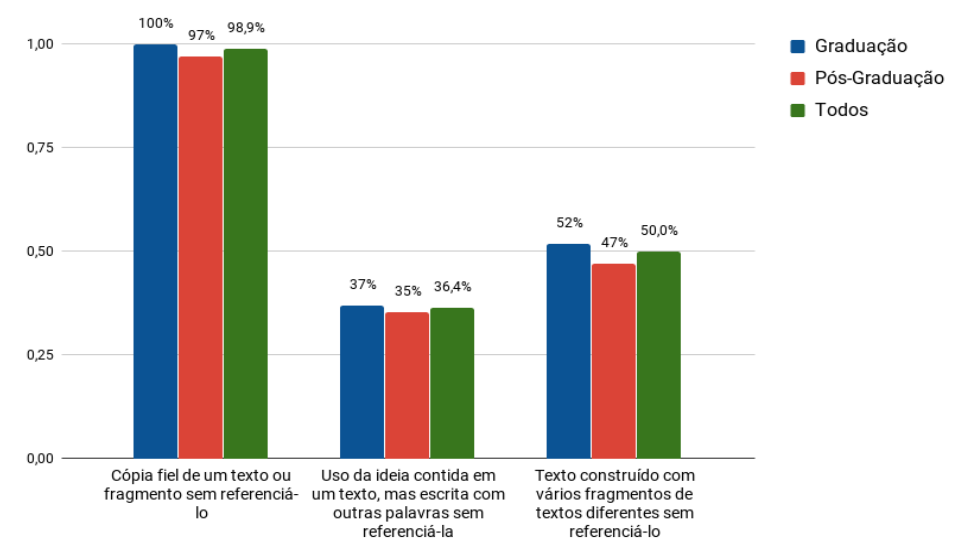

Figura 2: Tipos de plágio considerados pelos estudantes

\section{Q3: Os estudantes conhecem as normas de formatação de citações?}

Visando identificar o entendimento prático dos alunos perante as normas de formatação de citações diretas e paráfrases, foram elaboradas duas questões que contemplam exemplos de cada caso através de um texto-base retirado do livro 
"Docência na Universidade", de Masetto (1998, p. 9). Na Figura 3, são apresentados o texto da fonte original (Figura 3a) e os dois tipos de plágio considerados neste estudo. A Figura 3(b) caracteriza plágio verbatim, em razão de que possui uma citação direta que não está destacada por aspas, enquanto a Figura 3(c) contém um plágio parafraseado, uma vez que contém a cópia de ideias do texto original sem a devida referência.

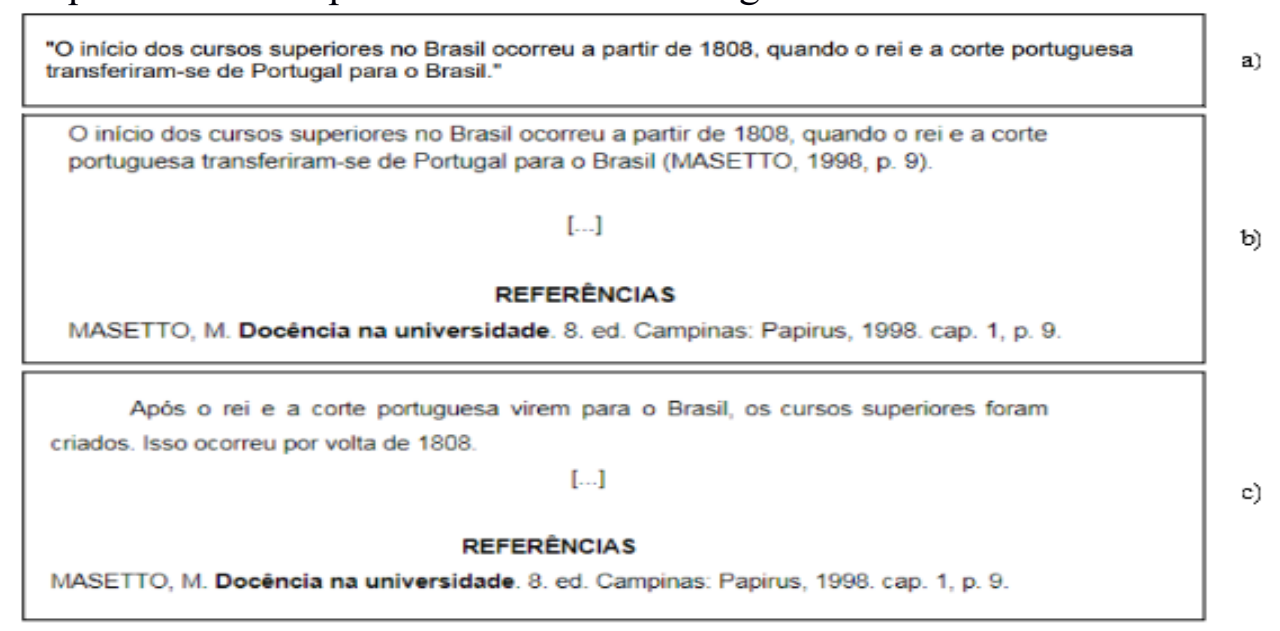

Figura 3: (a) Fonte original (b) citação direta sem aspas (c) Paráfrase sem referência

A Figura 4 apresenta o percentual de estudantes que considerou a citação direta sem aspas e a paráfrase sem referência (ilustradas na Figura 3) como sendo plágio. Apenas 21,6\% dos estudantes considerou a citação direta sem aspas como sendo plágio. Esse resultado expressa o conhecimento insuficiente perante as normas de formatação na inclusão de citações diretas em textos acadêmicos e/ou científicos por grande parte dos estudantes. Por outro lado, $60,2 \%$ dos respondentes consideraram a paráfrase sem referência como sendo plágio, o que mostra que a maioria dos estudantes reconhece a importância de referenciar quando ideias são copiadas de uma determinada fonte.

Acredita-se que as respostas se deram principalmente devido às dificuldades dos alunos em diferenciar as normas de citação direta e indireta, levando em consideração apenas se o trecho está ou não referenciado. Entretanto, deve-se destacar que mesmo havendo atribuição da fonte original, os trechos transcritos de outro autor devem estar corretamente destacados, evitando o plágio verbatim ou parafraseado.

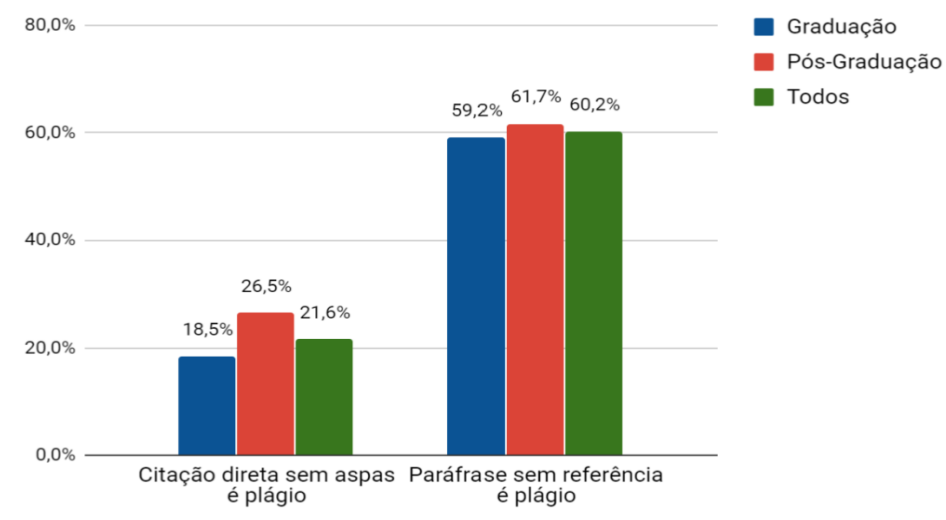

Figura 4: Estudantes que consideraram plágio a paráfrase sem referência e a citação direta sem aspas

\section{Q4: Quais situações você considera como sendo plágio?}

O objetivo desta questão foi identificar as situações que os estudantes 
consideram como sendo plágio. Foram definidas as seguintes situações: i) cópia fiel de um texto ou fragmento dele sem referenciá-lo; ii) uso da ideia contida em um texto, mas escrita com outras palavras sem referenciá-la; e iii) texto construído com vários fragmentos de textos diferentes sem referenciá-lo.

As respostas desta questão apresentaram uma contradição quando comparadas com as respostas da questão anterior (Q3). A matriz de confusão apresentada na Figura 5 ilustra que $37,5 \%$ dos respondentes consideraram como plágio o exemplo prático de uma paráfrase sem referência (Figura $3 \mathrm{c}$ ), entretanto, não consideraram como plágio a definição de escrita com outras palavras da ideia contida em um texto sem referenciá-la, sendo que ambos não referenciam a fonte original. Esse resultado reforça que os alunos apresentam pouco conhecimento sobre as normas de citação e os tipos de plágio, o que pode ocasionar casos de plágio não intencional.

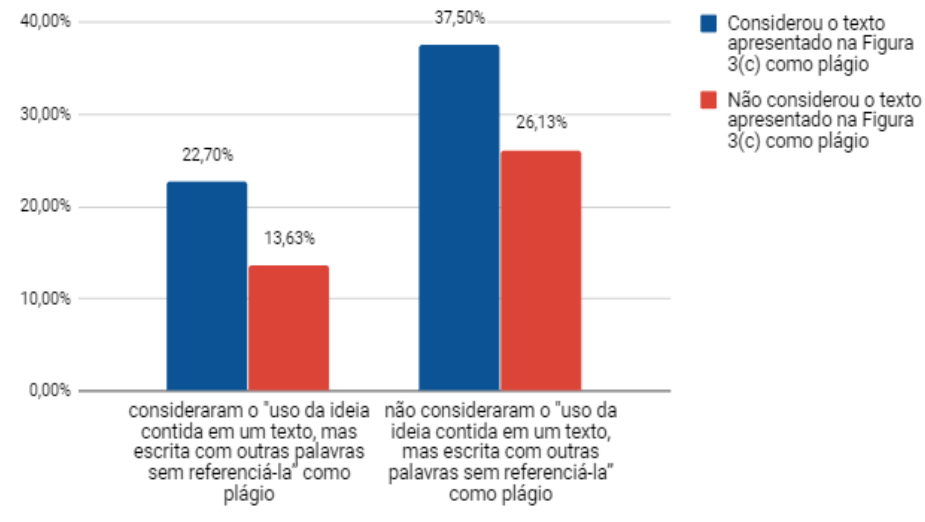

Figura 5: Relação entre a identificação prática do plágio de paráfrase e sua definição

\section{Q5: Quais os tipos de fontes de pesquisa utilizadas pelos estudantes?}

A busca por materiais bibliográficos na realização de pesquisas é de extrema importância, pois através dela é possível obter embasamento teórico para trabalhos acadêmicos e científicos. Fontes não-confiáveis podem conter informações inconsistentes, falsas ou até mesmo conter plágio sem o conhecimento do leitor. Alguns autores, como Silva et al. (2017), consideram que o fácil acesso de materiais digitais também têm contribuído para potencializar essa ação dentro das universidades. Nesse contexto, buscou-se por meio desta questão averiguar os tipos de fontes de pesquisa que os estudantes costumam utilizar para realização de trabalhos acadêmicos.

A Figura 6 apresenta as respostas classificadas em três grupos, conforme Guedes e Filho (2014): indivíduos que utilizam somente fontes confiáveis (biblioteca da universidade e municipal, Google Acadêmico, Portal de Periódicos Capes, SciELO e Anais de Congressos) representou $61,4 \%$ dos participantes. Somente fontes nãoconfiáveis (Wikipédia e em qualquer site que contenha a informação buscada) são utilizadas por $15,9 \%$ dos estudantes entrevistados. Cerca de $22,7 \%$ dos estudantes costumam pesquisar em fontes confiáveis e não-confiáveis.

Analisando os estudantes que pesquisam somente em fontes confiáveis, constatou-se que pós-graduandos possuem um percentual maior (15,10 pontos percentuais) em relação aos graduandos. O estudo também mostrou que os alunos de graduação pesquisam mais em fontes confiáveis que em fontes não confiáveis. 


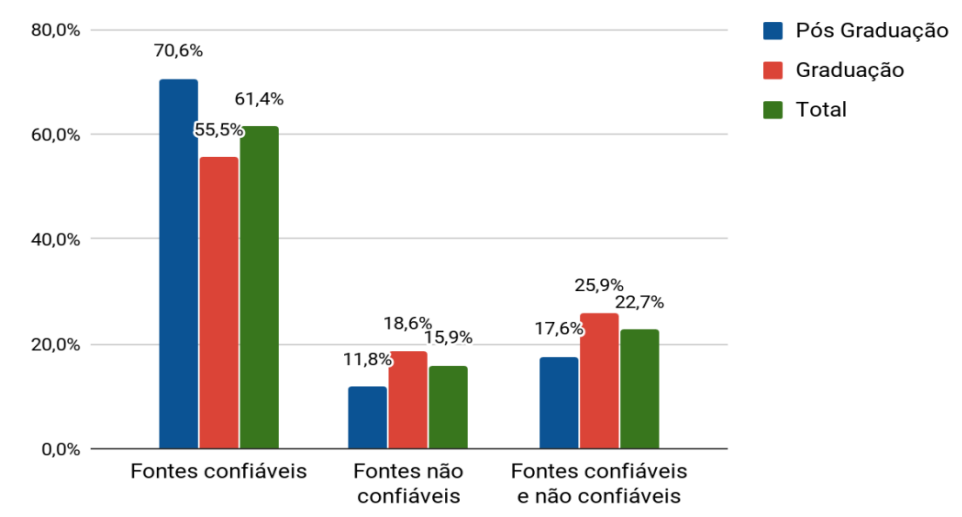

Figura 6: Fontes de pesquisa utilizadas

\section{Q6: Qual a ação dos estudantes ao encontrarem artigos retratados?}

A desonestidade e inconsistência científica está presente em diversas publicações em meios confiáveis, sendo os casos de artigos retratados. Um artigo pode ser retratado (desqualificado) por uma revista que o publicou devido à descoberta de erros ou fraudes (Fapesp, 2012). No entanto, esta questão visou identificar a conduta dos alunos ao depararem-se com tais artigos em suas pesquisas.

A Figura 7 apresenta os resultados obtidos, onde é possível perceber que a maioria dos entrevistados nunca encontrou uma publicação retratada $(65,9 \%)$. Entretanto, dentre os alunos que já encontraram artigos retratados, 20,4\% relatam utilizá-los como fonte de pesquisa. Pode-se perceber que até alunos $(14,7 \%)$ de pósgraduação utilizam artigos retratados, demonstrando não possuírem conhecimento de que este tipo de artigo foi considerado desqualificado.

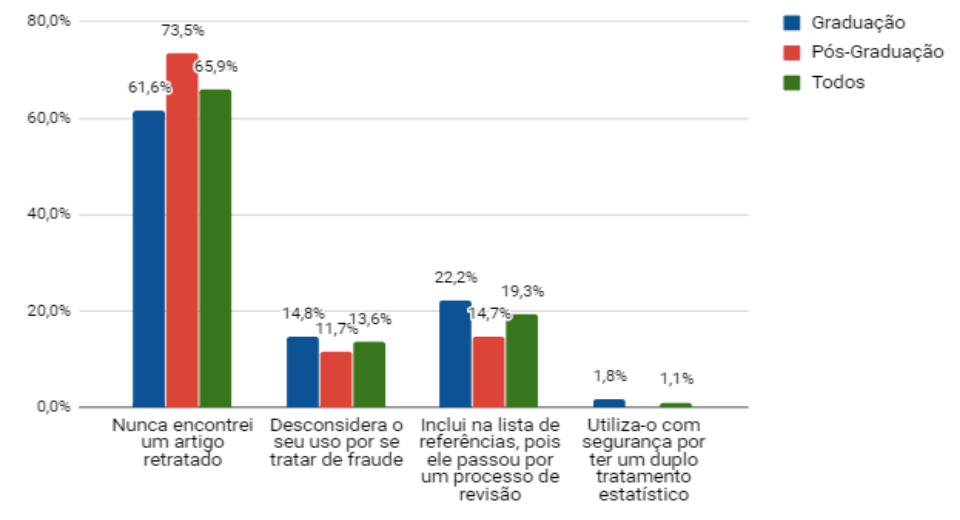

Figura 7: Utilização de artigos retratados

\section{Q7: Os alunos recebem orientações sobre plágio?}

Em seguida, foi avaliado se os estudantes recebem orientações sobre plágio no ambiente acadêmico. Neste caso, conforme a Figura 8, 81,8\% afirmaram terem recebido orientações por algum de seus professores, da mesma forma que os professores, quando questionados sobre as ações de prevenção da ocorrência de plágio, todos $(100 \%)$ afirmam ressaltar aos alunos a importância de atribuir créditos à fonte original ao utilizar trabalhos da literatura. 


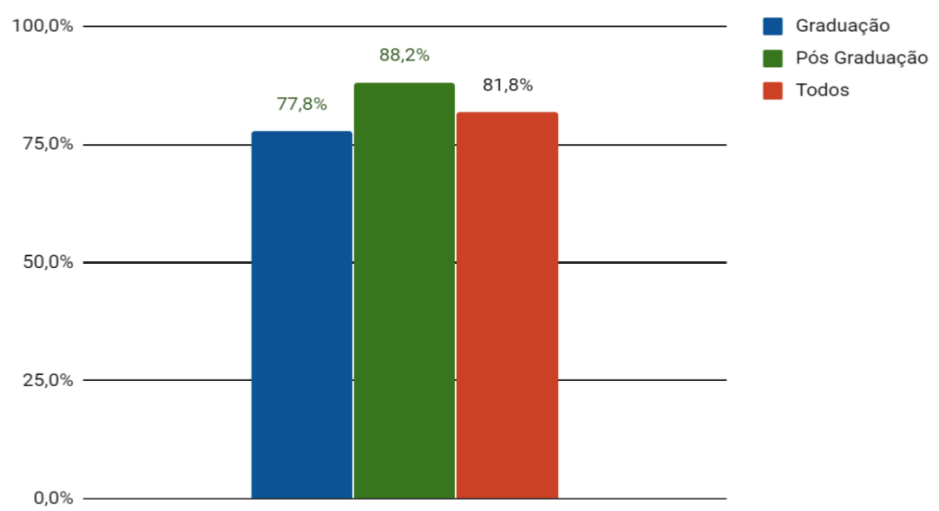

Figura 8: Percentual de alunos que responderam receber orientações sobre plágio

\section{Q8: Como os professores identificam o plágio?}

Além de ações preventivas, foi possível perceber que os professores utilizam métodos para detecção da ocorrência de plágio na correção de trabalhos acadêmicos. Dos professores entrevistados, 96,4\% afirmaram utilizar motores de busca (como o Google) para verificar se trechos dos trabalhos dos alunos foram copiados da internet. A cópia entre colegas também configura-se plágio, portanto $60,7 \%$ afirmaram verificar se o plágio foi realizado a partir do trabalho de colegas. Por fim, apenas 39,3\% dos entrevistados buscam identificar indícios de plágio por meio de ferramentas especializadas.

As ferramentas de detecção automática de plágio geralmente fazem a comparação do conteúdo entre dois documentos, atribuindo então um grau de similaridade entre eles. A utilização dessas ferramentas pode auxiliar o professor na análise de uma grande quantidade de trabalhos, uma vez que retornará os pares de documentos (suspeito-original) em ordem de similaridade. Os trechos identificados como possíveis ocorrências de plágio entre os documentos também são demarcados pelas ferramentas, facilitando a análise final pelo professor.

\section{Q9: Quais as ações adotadas ao identificar a ocorrência de plágio?}

Dentre os 28 professores entrevistados, $85,7 \%$ relatam que ao identificar um plágio conversam com o aluno, buscando minimizar o constrangimento. Além disso, $46,4 \%$ dos docentes possibilitam que o aluno refaça a atividade. Já apenas 32,14\% dos docentes relatam não oportunizar ao aluno refazer a atividade, além de descontar nota devido o ocorrido. Um dos professores entrevistados relata a falta de conhecimento de termos jurídicos e atitudinais para informar ao aluno que ele cometeu um plágio.

Q10: Você conhece as medidas definidas pela sua universidade que devem ser aplicadas a partir da identificação da ocorrência de plágio?

Conforme documento da Capes (2011), recomenda-se às instituições de ensino adotarem ações a fim de coibir o plágio no ambiente acadêmico. Nesse contexto, os professores foram questionados sobre as políticas internas da sua universidade aplicadas a partir da identificação da ocorrência de plágio. Constatou-se que 39,3\% dos professores desconhecem, enquanto apenas 14,3\% conhecem e 46,4\% consideram conhecer parcialmente.

Pode-se perceber com base nas respostas desta questão e da questão 8, que os professores não têm total conhecimento das políticas internas da universidade e sentemse inseguros para conversar e cobrar dos alunos quando ocorrem casos de plágio, 
conforme relatou um dos professores entrevistados.

\section{Q11: Qual a frequência de identificação de plágio na EaD?}

Por fim, os professores foram questionados sobre a percepção da ocorrência de plágio em cursos EaD, conforme apresenta o gráfico da Figura 9. Ao comparar os resultados entre os níveis de graduação e pós-graduação, observa-se que $28,6 \%$ dos docentes encontram frequentemente plágio na graduação, em contrapartida, na pósgraduação, este índice reduz para 6,7\%. Ainda, 19\% raramente encontram plágio na graduação e $33,3 \%$ na pós-graduação.

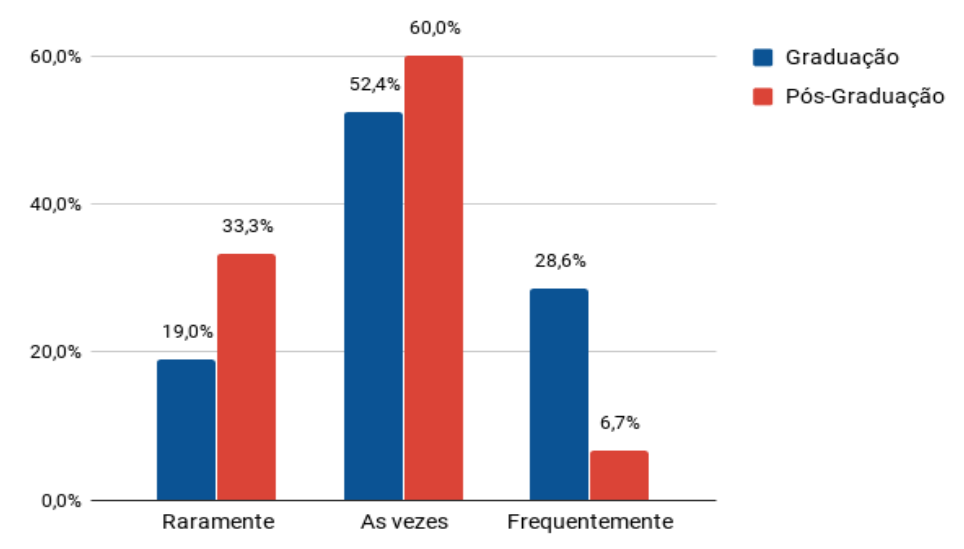

Figura 9: Percepção de plágio em cursos de Graduação e Pós-Graduação na EaD

Sob outra perspectiva, é notável a diferença entre a percepção de plágio dos professores em comparação com as respostas dos estudantes quando questionados se já cometeram plágio. Dos discentes participantes da pesquisa, $72,7 \%$ afirmam que nunca cometeram plágio, contrapondo os professores entrevistados que relataram encontrar plágio em trabalhos acadêmicos durante o semestre. Além disso, pode-se considerar que alguns estudantes cometem plágio não intencional, uma vez que a maioria dos entrevistados não identificou como sendo plágio a citação direta sem referência (conforme Figura 3b).

\section{Considerações finais}

Considerando o objetivo deste estudo, pode-se concluir que os professores consideram importante relatar os casos de plágio aos alunos para entendimento e correção, não se atendo apenas na punição. Outro ponto importante é que todos os professores relatam encontrar plágio na correção de trabalhos acadêmicos, entretanto, a grande parte dos alunos afirma nunca ter cometido plágio. Além disso, a maioria dos estudantes demonstrou falta de conhecimento acerca das normas de citação, além da dificuldade de identificar diferentes tipos de plágio, podendo-se concluir que os estudantes possivelmente cometem plágio não intencional.

Com base nessas conclusões, nota-se a importância da universidade promover ações com a comunidade acadêmica, com intuito de esclarecer as politicas internas da instituição e prevenir casos de plágio, em especial para os alunos de graduação que tendem a apresentar maiores dificuldades. Além disso, espera-se que os resultados possam contribuir para que os professores procurem trabalhar/conscientizar essas dificuldades em suas disciplinas.

Por fim, considerando a importância do assunto abordado na pesquisa e os resultados obtidos, recomenda-se para trabalhos futuros estender este estudo a outros cursos ofertados na $\mathrm{EaD}$ e cursos presenciais, visando identificar as principais 
dificuldades dos alunos em diferentes cursos e modalidades de ensino. $\mathrm{O}$ estudo também identificou que $60 \%$ dos professores não utilizam ferramentas de detecção automática de plágio, o que poderia auxiliá-los na verificação da originalidade de um número elevado de trabalhos acadêmicos. Sendo assim, considera-se necessário um estudo sobre a usabilidade dessas ferramentas.

\section{REFERÊNCIAS}

ANDERSON, M. S.; STENECK, N. H. The Problem of Plagiarism. Urologic Oncology: Seminars and Original Investigations, v. 29, n. 1, p. 90-94, 2011.

ALZAHRANI, S. et al. Using Structural Information and Citation Evidence to Detect Significant Plagiarism Cases in Scientific Publications. JASIST, v. 63, n. 2, p. 286-312, 2012.

BESSA, J. C. R. Referência ao discurso do outro: uma análise de problemas de relações de sentido entre discurso citado direto e discurso citante no gênero monográfico. Dissertação (Mestrado em Estudos da linguagem) - Universidade Federal do Rio Grande do Norte, Natal, 110 f. 2007.

CAPES. Orientações Capes - Combate ao plágio. 2011. Brasília. Disponível em: $<$ https://www.capes.gov.br/images/stories/download/diversos/OrientacoesCapes_CombateAoPlagio.p df $>$. Acesso em: 05 de abril de 2019.

FAPESP. Boas práticas: A fraude e suas ondas de choque. 2012. Disponível em: $<$ http://revistapesquisa.fapesp.br/wp-content/uploads/2012/12/009_boaspraticas_2022.pdf $>$. Acesso em: 05 de abril, 2019.

FAPESP. Código de Boas Práticas Científicas. 2014, p. 31. Disponível em: $<$ http://www.fapesp.br/boaspraticas/FAPESP-Codigo_de_Boas_Praticas_Cientificas_2014.pdf $>$. Acesso em: 10 de maio, 2019.

FERREIRA, M. M.; PERSIKE, A. O tratamento do plágio no meio acadêmico: o caso USP. Signótica, v. 26, n. 2, p. 519-540, 2014.

FIGUEIREDO, D. de C.; BONINI, A. Práticas discursivas e ensino do texto acadêmico: concepções de alunos de mestrado sobre a escrita. Linguagem em Discurso, Tubarão, v. 6, n. 3, p. 413-446, 2006.

INEP. (2016). Censo da Educação Superior 2016. Notas Estatísticas. Disponível em: $<$ http://download.inep.gov.br/educacao_superior/censo_superior/documentos/2016/notas_sobre_o_censo _da_educacao_superior_2016.pdf $>$. Acesso em: 10 de maio. 2019.

ITHENTICATE. SURVEY SUMMARY | Research Ethics: Decoding Plagiarism and Attribution in Research. 2013. Disponível em:<https://www.ithenticate.com/hs-fs/hub/92785/file-318578964pdf/docs/ithenticate-decoding-survey-summary-092413.pdf $>$. Acesso em: 10 de maio de 2019.

MASETTO, M. Docência na universidade. 8. Ed. Campinas: Papirus, 1998. Cap. 1, p. 9.

MCCABE, D. L. Cheating Among College and University Students : A North American Perspective. International Journal for Educational Integrity, v. 1, 2005.

PERTILE, S. de L., MOREIRA, V. P., ROSSO, P. Comparing and combining Content- and Citationbased approaches for plagiarism detection. JASIST 67(10): 2511-2526, 2016.

PERTILE, S. de L. e MEDINA, R. D. Desenvolvimento e Aplicação de um Método para Detecção de Indícios de Plágio. Em anais do XXII SBIE, Aracajú, 1673-1682, 2011.

SILVA, L. M., LUCE, B., SILVA FILHO, R. C. Avaliação De Critérios Para Fontes De Informações Na Área Da Saúde No Contexto Da Pós-verdade. IV Encontro Regional dos Estudantes de Biblioteconomia, Documentação, Ciência da Informação e Gestão da Informação - Regiões Sudeste, Centro-Oeste e Sul. 2017.

SILVA, O. S. F. (2008). Entre o plágio e a autoria: qual o papel da universidade. Revista Brasileira de Educação, 13(38), 357-368.

STEIN, B.; EISSEN, S. M. zu. Intrinsic Plagiarism Detection. In: ECIR. pp. 565-569, 2006.

YOUMANS, R. J. Does the Adoption of Plagiarism-detection Software in Higher Education Reduce Plagiarism?. Studies in Higher Education, v. 36, n. 7, p. 749-761, 2011. 